\title{
Study on the Development Path of The Maker Space Based on the Theory of Entrepreneurial Ecosystem
}

\author{
Lei Wang ${ }^{1, a}$, Yuan Zhou ${ }^{1, b}$, Ming-dong Jiang ${ }^{1,2, c, *}$ \\ ${ }^{1}$ School of Business Administration, Hohai University, Changzhou 213022, China \\ ${ }^{2}$ Study and Research Group of The thought of socialism with Chinese characteristics in the new er \\ a, Hohai University, Changzhou 213022, China \\ a15061119532@163.com, b945310382@qq.com, chhujmd@126.com \\ ${ }^{*}$ Corresponding author
}

Keywords: Maker space, Entrepreneurial ecosystem, Development path.

\begin{abstract}
Based on the theory of ecosystem, this paper collated the meaning of maker space, the essence of the culture and the characteristics. We structured the maker space into a complete entrepreneurial ecosystem, and the spirit was the unique cultural character of the space. Then we analyzed the characteristics of the space ecosystem from the internal and external levels. At last, through theoretical research and practice research, this paper explores the future development path of maker space from three aspects, such as enriching and optimizing the group of makers, gathering quality entrepreneurial resources and realizing seamless docking of makers and resources.
\end{abstract}

\section{Introduction}

The theoretical research on applying the theory of ecosystem to the maker space has been quite mature. In terms of spatial characteristics, most scholars believe that the maker space is different from the traditional hatchery such as incubators and science and technology parks. The entry threshold is low, and the number of makers is numerous and they paly multiple roles. The maker space possesses the attributes of "diversity" and has notable features such as "no borders, self-organization, and customization" in the overall dimension of space; in terms of spatial structure: Chen Wei analyzed the system structure of the maker space based on entrepreneurial ecosystem theory, and she believed that there are four spatial dimensions: "The maker spirit, maker ecosystem, resource ecosystem along with basic platform and public innovation policy". The maker spirit is the keynote of the development of the entrepreneurial ecosystem, and it leads the others three dimensions. The maker ecosystem and the resource ecosystem are intertwined and continue to promote the growth and development of entrepreneurial projects. This process is based on the basic platform of the maker space. In terms of space operation mechanisms: Jia Tianming analyzed the metabolic mechanism, the result-sharing-fault-tolerant and fault-trial dynamic mechanism, resource aggregation and integration mechanism and maker-resource collaborative symbiosis network mechanism of the ecosystem of the maker space. These four core operation mechanisms joint together and promote the success of entrepreneurship project.

In terms of theoretical research, there are already many scholars who have made significant explorations of the concept, connotation, structure, and operational mechanism of the maker space.

\section{The meaning of the ecosystem of the maker space}

The ecosystem of the maker space refers to the convergence of many entrepreneurial-related organizations on the same platform. These organizations focus on makers and provide them with comprehensive and multi-level entrepreneurial services. Similar to the natural ecosystem, the maker space has input of resources (environmental project plans and various service resources) and energy output (transformation of innovation results); energy flow (innovation atmosphere), information exchange (entrepreneurship experience sharing) and material circulation (creation of entrepreneurial projects) are continuously performed within the space. The various elements in the space for 
creation are mutually dependent, and they affect each other, develop on each other, and carry out close energy exchanges with the external environment, forming a complete entrepreneurial ecosystem.

\section{The structure of the ecosystem of the maker space}

The spirit of maker, as the cultural essence of the development of space, is a resource which is difficult to form but indispensable. Each maker space has its own personalized characteristics. For example some maker spaces use media imagery as its feature, and attract a large number of young entrepreneurs who are keen on media business. In maker space, makers enter with entrepreneurial dreams, but these dreams are often very small or very difficult to achieve, but some of them do contain new technology or new business model of creative projects, and some may even completely subvert the traditional industry model and may have a significant impact on people's life in the future. After the entry of maker space, makers seek a life of cooperation and symbiosis, they cooperate and innovate with other makers and advance as a group. In addition, the maker space contains the spirit of fault-tolerance. When compared with other economic activities, the entrepreneurship is known as high investment and high risk, because most entrepreneurial activities may fail due to financial difficulties or lack of market, and only a handful of projects can achieve the success of incubation, gain capital support and open market operations. However, the headcount of maker increases rather than decreases, we believe that it is because of the pursuit of innovation and the existence of fault-tolerance in the maker space that attracts a large number of makers to settle in.

\section{The characteristics of the ecosystem of the maker space}

As a newly-emerged product to promote continuous development of the economy, the maker space is different from the traditional technology incubator both in the internal and external aspects of space.

First in the internal aspect, the main resource has the ecology attribute of self-organization, self-organization refers to a phenomena that different kinds of resources spontaneous serve for a specific entrepreneurial project according to a tacit understanding. The entrepreneurial resources coordination without confusion, carry out their duties and make their own contribution. In the aspect of maker ecosystem, the lower entry threshold compared with the traditional incubator explains that more and more entrepreneurial projects choose to enter the maker space. The number of maker in the space is large, and the roles are diverse. In addition, the makers keep the interior essence of the maker space - maker spirit in mind. Most business plans have new technology or business model, the spirit of maker injects the space with fresh blood, and ensure the creativity and vitality of space.

Secondly, in the external aspect, different from the closed traditional incubator, the maker space has the characteristics of open sharing, market orientation and so on. A maker space is an open area with no fences, in addition to attracting more and more subject and the subject resources to settle in, it also consider neighboring universities, enterprises, communities and institutions as an important outside role of the maker. Market is the final destination of the maker space, the success hatching symbol of all entrepreneurial projects is getting capital support and starting market operation. Only when the customer's demand is met, the idea of the project can be transformed into entrepreneurial achievements. Therefore, the maker space is a customized ecological organization.

\section{Exploring the path of space development}

As the carrier of the trend: "mass entrepreneurship and innovation", the maker space's future economic benefits will have a direct impact on the development of regional economy. Through theoretical and practical research, this paper explores the future development path of public space from the following 3 aspects. 


\subsection{Enriching and optimizing the group of makers}

The vitality of the maker space ecosystem comes from the makers. Their creativity and creative thinking will have a direct impact on the success rate of the project incubation. Therefore, how to attract more makers to settle in the space and optimize the maker group has become the key challenge affecting the sustainable development in the future. On the one hand, the spatial operators can reduce the entry threshold, simplify entry condition and reduce the station price to attract a variety of makers, and use service resources of great quality to keep projects of great potential; on the other hand, we should strengthen the examination of makers, evaluate their ability and projects, and eliminate poor project in the development stage. In the later development stage of the project, the projects should also be examined and evaluated and the unsatisfied one eliminated.

\subsection{Gathering rich and high quality entrepreneurial resources}

High quality and rich entrepreneurial resources will have a strong attraction to potential makers and will greatly improve the success rate of business incubators. On the one hand, the spatial operators will raise the threshold of service access unit. At the same time, for the same property services (such as legal advice), several institutions should be invited in order to form a "internal competition " mechanism and retain high-quality service resources; on the other hand, the projects with low efficiency or even negative efficiency, advice will be given and the improvement urged.

\subsection{Seamless docking of makers and resources}

Seamless entrepreneurial projects depends on the healthy growth of entrepreneurial resources and entrepreneurial projects, the main resources should focus on maker groups to form a maker network system. In this system, makers and service unit closely transfer and share knowledge, experience and information. Through these activities, the Seamless docking of makers and resources can be achieved and the sustainable development and the project incubation rate improved.

\section{Acknowledgement}

This research was financially supported by the National Undergraduate Innovative Training Program(201710294102, 201610294107).

\section{References}

[1] X. Hou, X. Jin, and J. Wu, CAS from the perspective of public space characteristics and operational mechanism research, Information Magazine, vol.10, pp. 195-200+119, 2016.

[2] Q. L. Zhuang, L. H. Lei, and M. Y. Chen, Research on the PEST model based spatial ecosystem research, China Collective Economy, vol.26, pp. 46-48, 2017.

[3] S. Chen, L. Y. Xiang, and R. J. Yu, The public record space of entrepreneurial ecosystem characteristics, structure, mechanism and Strategy -- Taking Hangzhou as an example, dream town business economics and management, vol.11, pp. 35-43, 2015.

[4] Q. Wang, Construction of Entrepreneurial ecosystem of the maker space, Enterprise Economy, vol.10, pp. 5-9, 2016.

[5] T. M. Jia, L. H. Lei, and M. N. Wang, Set up space ecosystem: connotation, characteristics, structure and operating mechanism, Science and Technology Management Research, vol.11, pp. 8-14, 2017.

[6] Y. P. Li, and W. Chen, The current situation and prospect of Chinese public space research, China Science and Technology Forum, vol.05, pp. 12-18+56, 2017. 